\title{
European Group for Blood and Marrow Transplantation
}

National Cancer Institute

\section{Source}

National Cancer Institute. European Group for Blood and Marrow Transplantation. NCI

Thesaurus. Code C106397.

A non-profit organization that allows scientists and physicians participating in clinical bone marrow transplantation to share their experience and develop co-operative studies. 